\title{
Leptin induces cell proliferation and reduces cell apoptosis by activating c-myc in cervical cancer
}

\author{
YONG YUAN, JUAN ZHANG, LIN CAI, CAIXIA DING, XIAOMIN WANG, \\ HONGMEI CHEN, XIAN WANG, JUN YAN and JIANRONG LU
}

Department of Pathology, Shaanxi Cancer Hospital, Xi'an, Shaanxi 710061, P.R. China

Received January 18, 2013; Accepted March 18, 2013

DOI: $10.3892 /$ or.2013.2390

\begin{abstract}
Leptin may be involved in the pathogenesis of numerous cancer types by activation of cellular signaltransduction pathways. In this study, we analyzed the role of leptin and the mechanism(s) underlying its action in cervical carcinoma cells. Firstly, we examined the expression of leptin in 80 cases of cervical carcinoma using immunohistochemical staining. The results showed that the levels of leptin correlated significantly with the grades of cervical carcinoma. At the same time, the expression of leptin correlated positively with c-myc and its downstream gene, bcl-2. The expression of c-myc and bcl-2 was evaluated in leptin-treated HeLa cells by reverse transcription-polymerase chain reaction (RT-PCR) and western blotting. Recombinant leptin significantly activated the expression of bcl-2 and c-myc in HeLa cells. Finally, the apoptotic index, the proliferative activity and the expression levels of c-myc and bcl-2 were determined in the HeLa cells treated with silencing of leptin. We found that silencing of leptin inhibited the proliferation of HeLa cells and reduced the expression of bcl-2 and c-myc. Our data demonstrated that leptin interferes with the expression of oncogenic c-myc and anti-apoptotic bcl-2, and regulates cell turnover and facilitates the progression of cervical cancer.
\end{abstract}

\section{Introduction}

Carcinoma of the uterine cervix is one of the most common malignancies among women worldwide. Human papillomaviruses (HPVs) have been identified as the major etiological factor in cervical carcinogenesis (1). However, HPV infection alone is insufficient to trigger the tumorigenic cascade in human cervical cancer cells. This indicates that multiple steps, as well as multiple factors, may be necessary for the develop-

Correspondence to: Dr Jianrong Lu, Department of Pathology, Shaanxi Cancer Hospital, YanTa West Street, No. 309, Xi'an, Shaanxi 710061, P.R. China

E-mail: lujr535@126.com

Key words: cervical cancer, leptin, c-myc, bcl-2, proliferation, apoptosis ment of cervical cancer. Leptin is a metabolic hormone that is required for the maintenance of normal energy balance and body weight $(2,3)$. It is a multifunctional peptide hormone with wide ranging biological activities including appetite regulation, bone formation, reproductive function and angiogenesis (4-6). These biological activities indicate that the leptin system may be involved in the development and progression of neoplasms (7). Leptin exerts its actions through its specific receptors present in a variety of tissues localized to the cell membrane (8). The leptin receptor belongs to a family of class I cytokine receptors, which typically contain a cytokine receptor homologous domain in the extracellular region (9). Stimulation of the leptin receptor has been reported to activate multiple signaling pathways such as JAK/STAT, ERK and PI3K/AKT $(10,11)$. Here, we hypothesized that leptin expression may correlate with the progression of cervical tumors. Our previous investigation showed that leptin significantly increased the growth of HeLa cervical cancer cells in a dose-dependent and time-dependent manner, and leptin significantly upregulated c-myc mRNA and protein expression in HeLa cells (12). In the present study, we analyzed the relationship between leptin expression and the clinical pathology of cervical cancer and examined the relationships between leptin and c-myc and bcl-2. Furthermore, we treated HeLa cells with recombinant leptin or silencing of leptin and explored the effect on the cellular proliferation and apoptosis and analyzed the mechanisms of leptin involved in cervical carcinoma progression in vitro.

\section{Materials and methods}

Patients and specimens. Tissue samples were obtained from 80 women who underwent partial or radical hysterectomy due to cervical lesions during the period 2008-2010. The age of the patients ranged from 28 to 72 years (mean 52.8 years). All samples were pathologically confirmed cervical intraepithelial neoplasia (CIN) or squamous cell carcinoma (SCC). No patients had received treatment before tumor excision. Tumor samples had previously been fixed in $10 \%$ buffered formaldehyde solution and embedded in paraffin blocks for routine histological examination.

Immunohistochemistry. The immunohistochemical analysis of leptin, Ki-67, c-myc and bcl-2 was carried out in representative tissue sections using antibodies for leptin (rabbit polyclonal 
Ab, dilution 1:100); for bcl-2 (mouse monoclonal antibody, dilution 1:100) (both from Boster, China); for c-myc (goat polyclonal Ab, dilution 1:200) (Santa Cruz Biotechnology, Inc, Santa Cruz, CA, USA). Other antibodies were working solutions. Final stainings were performed with DAB staining system (Maxin, China). Slides were counterstained with hematoxylin. In the negative controls the primary antibody was omitted. The expression of leptin, bcl-2, Ki-67 and c-myc was analyzed in 10 different tumor fields, and the mean percentage of tumor cells with positive staining was evaluated. The expression of the studied proteins in the cancer samples was classified using a four-point scale: $0,<10 \%$ positive cells; $1+$, $10-50 \%$ positive cells with weak staining; $2+,>50 \%$ positive cells with weak staining; $3+,>50 \%$ positive cells with strong staining.

Cell culture and colorimetric MTT assay. The HeLa cell line was grown in Dulbecco's modified Eagle's medium (DMEM) supplemented with $10 \%$ fetal bovine serum (FBS). For treatment, cells were seeded at a density of $1 \times 10^{6} / 100-\mathrm{mm}$ tissue culture dish. Cells were serum-deprived overnight and transfected with the leptin siRNA for 24,48 or $72 \mathrm{~h}$. The cells were then incubated with 3-(4,5-dimethylthiazol-2-yl)-2,5-diphenyltetrazolium bromide (MTT; $0.5 \mathrm{mg} / \mathrm{ml}$ ) for $4 \mathrm{~h}$ at $37^{\circ} \mathrm{C}$. After removal of MTT, $150 \mu 1$ of dimethyl sulphoxide (DMSO) was added to the cells, and the absorbance was measured at $540 \mathrm{~nm}$ using a microplate reader.

Flow cytometry and TUNEL analysis. For flow cytometric analysis, cells were maintained at a density of $3 \times 10^{5}$ cells in $60-\mathrm{mm}$ plates. After transfection with leptin siRNA, the cells were harvested, rinsed with ice-cold phosphate-buffered saline (PBS), and fixed with ice-cold $70 \%$ ethanol. The cells were centrifuged for $5 \mathrm{~min}$ at $1,000 \mathrm{x} \mathrm{g}$ and resuspended in PBS containing $5 \mathrm{mM}$ of ethylenediaminetetraacetic acid (EDTA) and RNase A (1 mg/ml). After incubation for $1 \mathrm{~h}$ at $37^{\circ} \mathrm{C}$, the cells were treated for $15 \mathrm{~min}$ with fluorescein isothiocyanate (FITC)-labeled Annexin V and propidium iodide (PI), according to the supplier's protocol (Dako, Denmark), and then were analyzed with a flow cytometer. TUNEL analysis was employed using the apoptosis detection kit (Maixin, China) according to the manufacturer's protocol. The apoptotic cells in 10 different fields were counted, and the apoptotic index was calculated as the ratio of apoptotic cells over total cells.

Reverse transcription-polymerase chain reaction (RT-PCR). Total RNAs were extracted using TRIzol reagent (Invitrogen Life Technologies, Carlsbad, CA, USA), and single-stranded cDNA was synthesized from $1 \mu \mathrm{g}$ of total RNA using PrimeScript $^{\mathrm{TM}}$ RT reagent kit following the protocol recommended by the manufacturer (Takara, Japan). PCR primers were as follows: c-myc, sense, GCCACGTCTCCACACATCAG and antisense, TCTTGGCAGCAGGATAGTCCTT; Bcl-2, sense, TTTCTCATGGCTGTCCTTCAGGGT, and antisense, AGGTCTGGCTTCATACCACAGGTT. In addition, specific primers for the 18S RNA were used as control. The primers were sense, 5'-GAGGGAGCCTGAGAAACGG-3', and antisense, 5'-GTCGGGAGTGGGTAATTTGC-3'. Finally, 30 cycles of PCR amplification were carried out.
RNA interference. Using a fluorescein-labeled (FAM) siRNA (GenePharma Co., Ltd., China), multiple targets were designed against leptin mRNA (13), and specificity was confirmed using the BLAST tool on the NCBI website. A non-specific scramble control sequence was also generated. HeLa cells were transfected with siRNAs at a final concentration of $100 \mathrm{nM}$ Lipofectamine ${ }^{\mathrm{TM}} 2000$ according to the manufacturer's instructions.

Western blotting. Total extracts were obtained in the supernatant. Approximately $20 \mu \mathrm{l}$ of the samples was resolved on $10 \%$ SDS-PAGE, and transferred to PVDF membranes. Western blot analyses were conducted using the following antibodies: rabbit polyclonal antibodies for leptin (1:200); a mouse polyclonal antibody for c-myc (1:500) and a rabbit polyclonal antibody for $\beta$-actin (1:200) to detect the corresponding proteins. The peroxidase-conjugated goat anti-mouse/rabbit secondary antibody (Sigma, St. Louis, MO, USA) was used. Immunodetection was carried out using enhanced chemiluminescence (Pierce Biotechnology, Inc., Rockford, IL, USA) according to the manufacturer's instructions.

Statistical analysis. Statistical analysis was carried out using SPSS 11.5 software. The relationships between the expression levels of leptin and the clinicopathologic alterations of cervical cancer were determined using Spearman correlation analysis. The results of RT-PCR, western blotting, MTT assay and apoptosis were analyzed using the paired or unpaired Student's $\mathrm{t}$-test, and a value of $\mathrm{p}<0.05$ was assumed to indicate a statistically significant result. All experiments were independently carried out thrice in triplicate.

\section{Results}

Leptin expression correlates with the progression of cervical cancer. Immunohistochemistry was employed to investigate the expression of leptin, bcl-2, c-myc and Ki-67 in the cervical cancer samples (Fig. 1). As shown in Table I, 21 cases in the 62 samples of cervical cancer showed leptin-positive expression (33.9\%). Ten cases of the 23 squamous cell carcinoma grade III $(43.5 \%), 8$ cases of the 26 squamous cell carcinoma grade II $(30.8 \%), 3$ cases of the 13 squamous cell carcinoma grade I (23.1\%) and 3 cases of the 18 cervical intraepithelial neoplasia (CIN) samples (16.7\%) showed leptin-positive staining. Our data revealed that leptin expression was significantly correlated with the grade of cervical neoplasia $(\mathrm{p}<0.05)$. Analysis of the relationships between leptin and the studied proteins showed a statistically significant positive correlation between leptin and anti-apoptotic protein bcl-2 $(\mathrm{p}<0.05)$ as well as between leptin and oncogenic c-myc $(\mathrm{p}<0.05)$. Leptin immunoactivity was correlated negatively with the Ki-67 labeling index $(\mathrm{p}<0.05)$.

Leptin affects apoptosis and proliferation activity of cervical cancer cells. Our previous study revealed that recombinant leptin dose-dependently $(0,50$ and $100 \mathrm{nM})$ stimulated cell proliferation and reduced the apoptosis in cervical cancer HeLa cells (12). To further study the functions of leptin in HeLa cell growth, we knocked down the expression of leptin in HeLa cells by leptin siRNA as described in Materials and 
Table I. Expression of the studied proteins in cervical neoplasia.

\begin{tabular}{lcccr}
\hline & $\begin{array}{c}\text { Leptin } \\
\mathrm{n}(\%)\end{array}$ & $\begin{array}{c}\mathrm{bcl}-2 \\
\mathrm{n}(\%)\end{array}$ & $\begin{array}{c}\text { Ki-67 } \\
\mathrm{n}(\%)\end{array}$ & $\begin{array}{c}\text { c-myc } \\
\mathrm{n}(\%)\end{array}$ \\
\hline CIN & $3(16.7)$ & $4(22.2)$ & $7(38.9)$ & $4(22.2)$ \\
SCC & & & & 18 \\
Grade I & $3(23.1)$ & $5(38.5)$ & $6(46.2)$ & $6(26.1)$ \\
Grade II & $8(30.8)$ & $16(61.5)$ & $17(65.4)$ & $11(42.3)$ \\
Grade III & $10(43.5)$ & $16(69.6)$ & $22(95.7)$ & $12(52.2)$ \\
\hline
\end{tabular}

CIN, cervical intraepithelial neoplasia; SCC, squamous cell carcinoma.

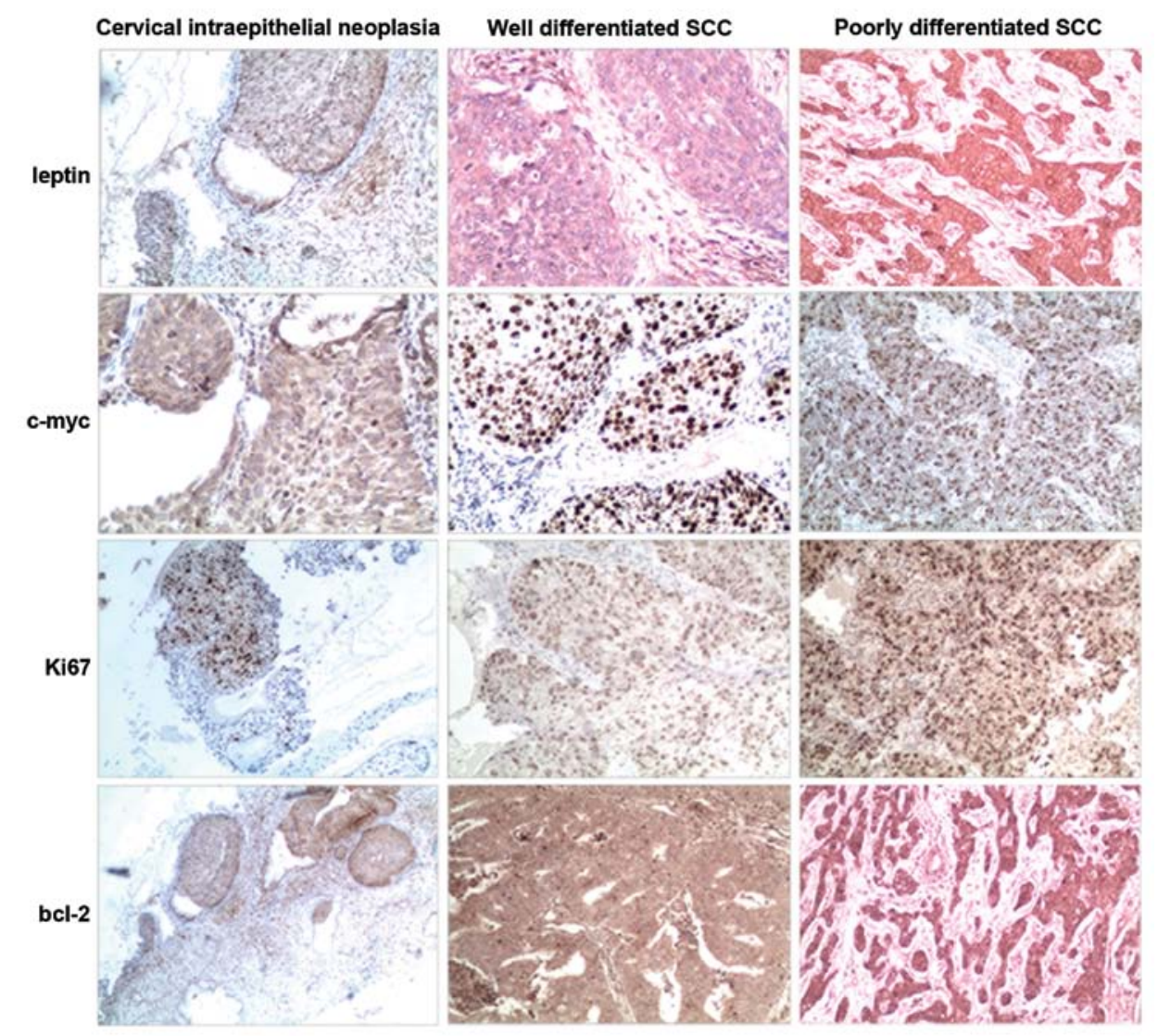

Figure 1. Immunohistochemical staining of leptin, bcl-2, c-myc and Ki-67 in cervical cancer. The localization of leptin was preserved in the cytoplasm, and the expression of leptin was correlated with the grade of cervical neoplasia $(\mathrm{p}<0.05)$. Strong c-myc staining was noted in the primary tumor in $>50 \%$ of cancer cells. Cytoplasmic immunoreactivity to bcl-2 was higher in the cases of squamous cell carcinoma (SCC) compared to cervical intraepithelial neoplasia (CIN). $\mathrm{Ki}-67$ was expressed in nuclei, and the expression of $\mathrm{Ki}-67$ was lower in CIN and well differentiated SCC when compared to the expression level in the poorly differentiated SCC cases.

methods. Our results showed that leptin was successfully silenced by leptin siRNA at both the mRNA level (Fig. 2D) and the protein level (Fig. 4B). Upon transfection, an apparent suppression in cell growth was observed in the leptin-silenced HeLa cells (Fig. 2). At $72 \mathrm{~h}$ after transfection, the viability of the leptin siRNA-transfected HeLa cells decreased by $\sim 80 \%$ compared with the controls according to the MTT assay $(\mathrm{p}<0.05)$ (Fig. 2A). Apoptosis was detected by flow cytometric analysis and TUNEL staining. As shown in Fig. 2C the apoptotic index of the cells with knockdown of leptin significantly increased when compared to the apoptotic index in the nega- tive control cells $(\mathrm{p}<0.05)$. Flow cytometric analysis revealed that leptin RNAi increased the apoptosis of HeLa cells from $15.4 \pm 2.4$ to $29.5 \pm 3.2 \%$ ( $\mathrm{p}<0.05$ ) (Fig. $2 \mathrm{~B}$ ). These results indicate that knockdown of leptin inhibits the proliferative activity and stimulates the apoptosis in cervical cancer cells.

Leptin regulates the expression of $c-m y c$ and bcl-2 in HeLa cervical cancer cells. To investigate the mechanism(s) involved in leptin-mediated cell proliferation in HeLa cells, the expression of bcl-2 and c-myc was initially measured by RT-PCR following treatment with recombinant leptin in HeLa cells. As 
A

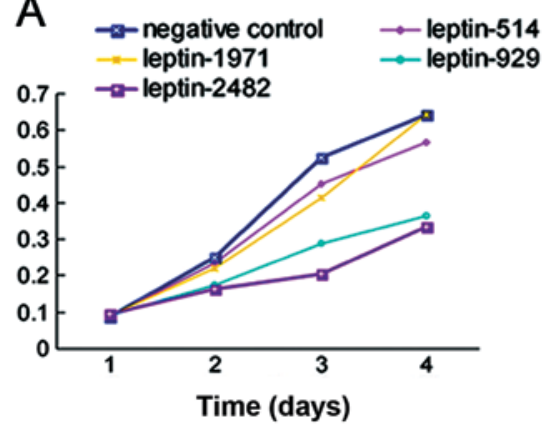

C
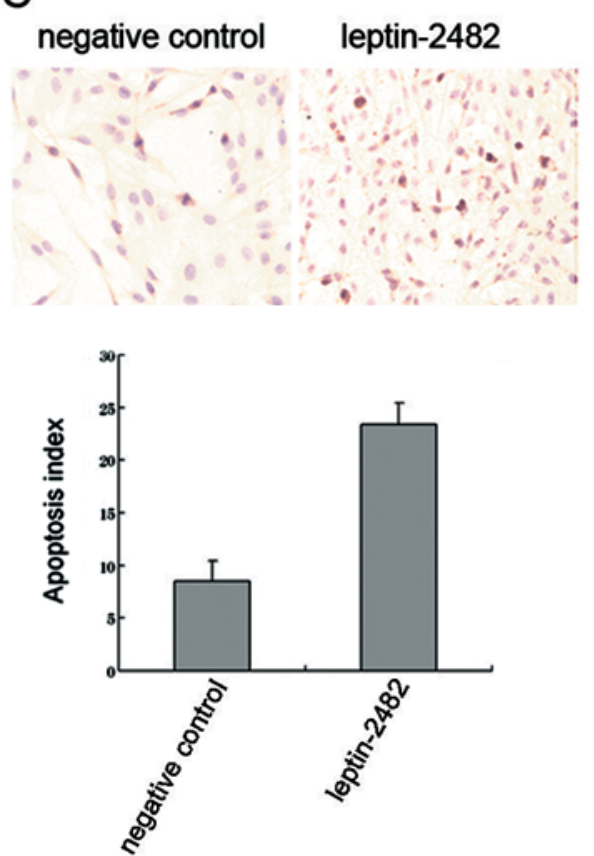

B
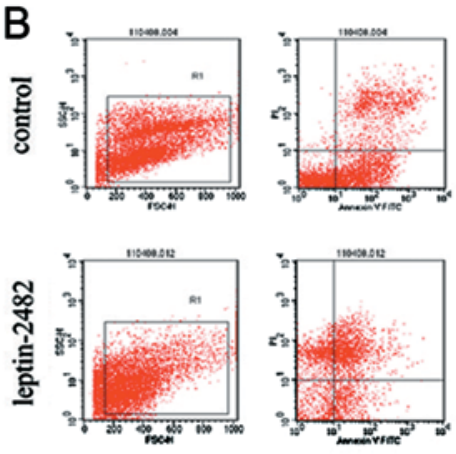

D
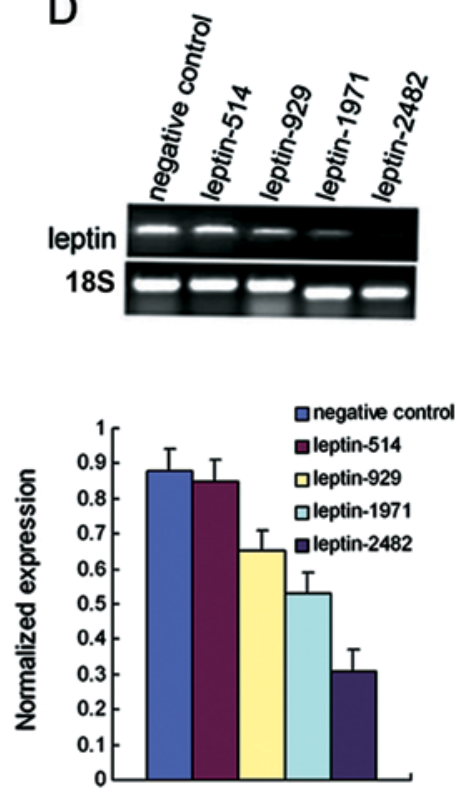

Figure 2. Silencing of leptin reduces cell proliferation and induces apoptosis in HeLa cells. (A) The MTT assay indicated that the growth rate of the leptin-2482 group was significantly lower than the other interference groups and the negative control group after transfection for 24,48 and 72 h. (B) Flow cytometric analysis showed that leptin RNAi increased the apoptosis of HeLa cells from $15.4 \% \pm 2.4$ to $29.5 \pm 3.2 \%$ (p<0.05) after transfection with leptin-2482. (C) The TUNEL analysis revealed that leptin RNAi significantly induced apoptosis in HeLa cells, and the apoptosis index of HeLa cells transfected with leptin-2482 was significantly increased when compared to the negative control (NC siRNA) $(n=3, p<0.05)$. (D) RT-PCR analysis revealed that leptin mRNA was reduced by $57 \%$ following transfection with leptin-2482 $(n=3, p<0.05)$.

shown in Fig. 3A, the mRNA level of c-myc in HeLa cells following leptin treatment markedly increased when compared with the blank control $(\mathrm{p}<0.05)$. Moreover, the mRNA level of bcl-2 was significantly increased compared with the control groups $(\mathrm{p}<0.05)$. Similarly, the immunoblot analysis (Fig. 3B) revealed that leptin induced the expression of c-myc and bcl-2 in HeLa cells. These results suggest that leptin leads to the activation of c-myc and bcl-2, which are known to regulate apoptosis. Then RNA interference of leptin was employed to gain further insight into the role of leptin in HeLa cells. Using western blot analysis (Fig. 4B), a significant reduction in leptin protein levels was noted in cells treated with siRNA, relative to the negative control ( $\mathrm{p}<0.05 ; 48 \mathrm{~h}$ ). The activity of $\mathrm{c}-\mathrm{myc}$ and bcl-2 (Fig. 4) as detected by RT-PCR and western blotting revealed that silencing of leptin inhibited the expression of c-myc $(p<0.05)$, as well as bcl-2 $(p<0.05)$. This reinforced the finding that leptin is an efficient regulator of c-myc signaling.

\section{Discussion}

The development and progression of cancer involve a series of molecular changes affected by the interaction of a cell and its environment. Such processes as angiogenesis, lymphangiogenesis, cell motility, proliferation, and cell apoptosis are also important. Leptin, a product of the obese (ob) gene, is a neuroendocrine hormone that has attracted attention since its identification in 1995 (2,3). Previous reports suggest that leptin is overexpressed in various types of cancer cells and plays a role in the development and/or progression of a variety of malignancies including colon $(14,15)$, gastric (16), endometrial (17), ovarian (18) and breast cancers $(19,20)$. In the present study, we firstly examined the prevalence of the expression of leptin and several genes which regulate apoptosis and proliferation activity in 80 samples of cervical neoplasia. Leptin protein was detected in $33.9 \%$ of the examined cases. 
A
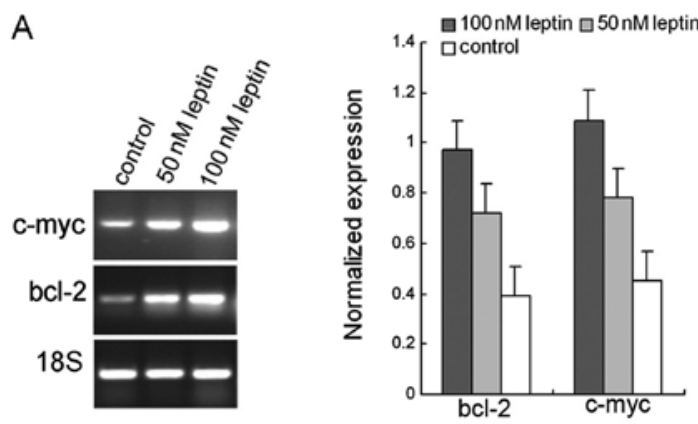

B

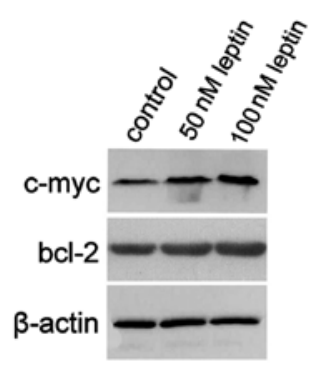

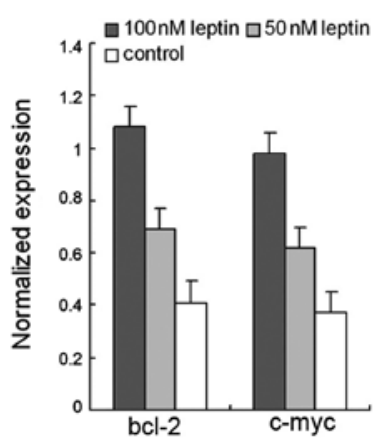

Figure 3. Leptin activates the expression of c-myc and bcl-2. HeLa cells were serum-starved for $16 \mathrm{~h}$ followed by treatment with different concentrations of leptin for $48 \mathrm{~h}$. (A) RT-PCR and (B) western blotting revealed that, following treatment with leptin, the protein levels of c-myc and bcl-2 were increased with a corresponding increase in their mRNA level in a dose-dependent manner in HeLa cells. Expression of mRNA and protein was normalized to the quantity of internal standard as shown in the histograms $(n=3, p<0.05)$.

The samples with high leptin expression showed significantly poorer differentiation. In contrast, reduced leptin expression was noted in cervical intraepithelial neoplasia and well differentiated cancer. We also observed a significant correlation between leptin expression and the Ki-67 labeling index in the cervical cancers. This suggests that leptin, through an autocrine mechanism, activates cervical cancer to increased progression of the disease, and the expression level of leptin may provide useful information for estimating the malignancy of cervical cancer.

Leptin was previously reported to stimulate the proliferation of various types of tumor cells. Mauro et al (21) observed that leptin stimulated the proliferation of MCF-7 breast cancer cells in vivo and this action was correlated with increased expression of E-cadherin and cyclin D1. Rouet-Benzineb et al (22) reported that leptin enhanced the apoptosis of human colon cancer HT-29 cells probably through activation of the NF- $\mathrm{kB}$ pathways. Escobar-Morreale and San Millán (23) and Sharma et al (24) observed increased proliferation by leptin in endometrial and ovarian cancer cells. Moreover, Saxena et al (10) found the leptin promoted invasion and migration of hepatocellular carcinoma cells. Our previous experiment revealed that recombinant leptin significantly induced proliferation and reduced apoptosis in HeLa cells (12). Here, we found that leptin siRNA efficiently reversed the growth of HeLa cells. Our experiments clearly showed that leptin has an oncogenic effect on HeLa cells and this oncogenic effect is due to a combination of cell proliferation and inhibition of apoptosis by leptin.
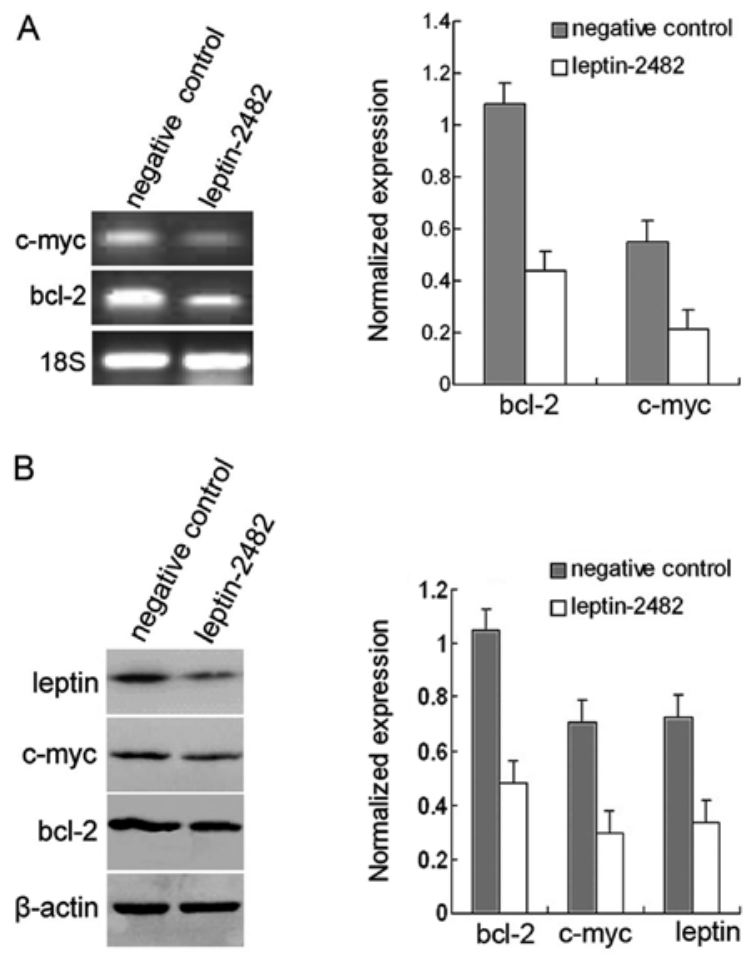

Figure 4. Leptin siRNA suppresses the protein and mRNA levels of leptin, c-myc and bcl-2 in HeLa cells. (A) The mRNA levels were measured by RT-PCR. The relative expression of c-myc and bcl-2 mRNA was reduced in HeLa cells transfected with leptin siRNA (leptin-2484) compared to the negative control cells. (B) The protein expression of leptin, c-myc and bcl-2 was reduced in leptin-2484 cells when compared to these levels in the control cells. Expression of mRNA and protein was normalized to the quantity of the internal standard as shown in the histograms $(n=3, p<0.05)$.

The c-myc gene was found to be the cellular homolog of retroviral v-myc oncogene about 30 years ago (25). It is located on chromosomal region 8q24.1 and encodes a nuclear phosphoprotein (26) and is generally recognized as an important regulator of proliferation, growth, differentiation and apoptosis (27). c-myc regulates transcription from its targets through several mechanisms, including recruitment of histone acetylases, chromatin modulating proteins, basal transcription factors and DNA methyltransferase (28). Oncogenic alterations of myc are commonly induced by events such as point mutations, gene amplification, chromosomal translocation, viral insertion at the myc locus, and resistance of myc protein to ubiquitin-mediated proteolysis and enhanced transcription or translation by other oncogenic signaling pathways. Expression of the c-myc oncogene or its protein product is elevated in virtually all types of malignant diseases (29). Therefore, it is also accepted that the deregulation of myc expression is a major event in cancer pathogenesis or progression (30). Groups of genes involved in cell cycle regulation, metabolism, ribosome biogenesis, protein synthesis and mitochondrial function are overrepresented in the myc target gene network. Bcl-2, which is regarded as a significant target gene, has been investigated for prognostic significance in various malignancies, including carcinoma of the cervix $(31,32)$. Bcl-2 has been shown in some studies as an independent predictor of poor prognosis in carcinoma of the cervix (33). To elucidate the target regulators involved in leptin-mediated induction of the 
cancerous properties of HeLa cells, we examined the effect of leptin on the activation of c-myc and bcl-2. Our data showed that leptin rapidly stimulated c-myc and bcl-2 thus activating these key signaling regulators associated with cell growth. In addition, gene silencing of leptin in HeLa cell lines abrogated c-myc activation as well as the expression of anti-apoptotic gene bcl-2, suggesting that leptin-mediated HeLa cell growth is due to the modulation of oncogene c-myc and anti-apoptotic gene bcl-2 expression.

In conclusion, leptin expression was significantly correlated with the grade of cervical carcinoma, as well as a high Ki-67 labeling index. Furthermore, the levels of leptin were significantly positively correlated with oncogene c-myc and its target gene, bcl-2. This suggests an important role for leptin in cervical carcinogenesis. Moreover, our data revealed that leptin regulates the expression of c-myc and bcl- 2 in HeLa cells, and the molecular mechanism responsible for leptin-mediated cell proliferation in cervical cancer was further elucidated, thus establishing a direct association between leptin and cervical carcinogenesis. Our findings have potential clinical implication in the prevention of development and progression of cervical cancer.

\section{Acknowledgements}

The present study was supported by a grant from the Science and Technology Department of Shaanxi, China (2010k1403-11). We are grateful to Dr Zhizhong Wang for help with the statistical analysis and Dr Weidong Lü for his critical comments concerning the manuscript.

\section{References}

1. Jemal A, Bray F, Center MM, et al: Global cancer statistics. CA Cancer J Clin 61: 69-90, 2011.

2. MacDougald OA, Hwang CS, Fan H, Lane MD, et al: Regulated expression of the obese gene product (leptin) in white adipose tissue and 3T3-L1 adipocytes. Proc Natl Acad Sci USA 92: 9034-9037, 1995.

3. Halaas JL, Gajiwala KS, Maffei M, et al: Weight-reducing effects of the plasma protein encoded by the obese gene. Science 269 543-546, 1995.

4. Huang L and Li C: Leptin: a multifunctional hormone. Cell Res 10: 81-92, 2000 .

5. Bouloumié A, Drexler HC, Lafontan M and Busse R: Leptin, the product of $\mathrm{Ob}$ gene, promotes angiogenesis. Circ Res 83: 1059-1066, 1998.

6. Sierra-Honigmann MR, Nath AK, Murakami C, et al: Biological action of leptin as an angiogenic factor. Science 281: 1683-1686, 1998.

7. Somasunder P, McFadden DW, Hileman SM and Vona-Davis L: Leptin is a growth factor in cancer. J Surg Res 116: 337-349, 2004

8. Bjorbaek C, Uotani S, da Silva B and Flier JS: Divergent signaling capacities of the long and short isoforms of the leptin receptor. J Biol Chem 272: 32686-32695, 1997.

9. Tartaglia LA: The leptin receptor. J Biol Chem 272: 6093-6096, 1997.

10. Saxena NK, Sharma D, Ding X, et al: Concomitant activation of the JAK/STAT, PI3K/AKT, and ERK signaling is involved in leptin-mediated promotion of invasion and migration of hepatocellular carcinoma cells. Cancer Res 67: 2497-2507, 2007.

11. Yin N, Wang D, Zhang H, et al: Molecular mechanisms involved in the growth stimulation of breast cancer cells by leptin. Cancer Res 64: 5870-5875, 2004.
12. Yuan Y, Wang X, Lu J, et al: Effects of leptin on biological behavior of cervical cancer Hela cells and its mechanism. Chin J Clin Exp Pathol 28: 162-165, 2012 (In Chinese).

13. Elbashir SM, Harborth J, Weber K and Tuschl T: Analysis of gene function in somatic mammalian cells using small interfering RNAs. Methods 26: 199-213, 2002.

14. Hoda MR, Keely SJ, Bertelsen LS, Junger WG, Dharmasena D and Barrett KE: Leptin acts as a mitogenic and antiapoptotic factor for colonic cancer cells. Br J Surg 94: 346-354, 2007.

15. Ogunwobi OO and Beales IL: The anti-apoptotic and growth stimulatory actions of leptin in human colon cancer cells involves activation of JNK mitogen activated protein kinase, JAK2 and PI3 kinase/Akt. Int J Colorectal Dis 22: 401-409, 2007.

16. Pai R, Lin C, Tran T and Tarnawski A: Leptin activates STAT and ERK2 pathways and induces gastric cancer cell proliferation. Biochem Biophys Res Commun 331: 984-992, 2005.

17. Koda M, Sulkowska M, Wincewicz A, Kanczuga-Koda L, Musiatowicz B, Szymanska M and Sulkowski S: Expression of leptin, leptin receptor, and hypoxia-inducible factor 1 alpha in human endometrial cancer. Ann NY Acad Sci 1095: 90-98, 2007.

18. Choi JH, Park SH, Leung PC and Choi KC: Expression of leptin receptors and potential effects of leptin on the cell growth and activation of mitogen-activated protein kinases in ovarian cancer cells. J Clin Endocrinol Metab 90: 207-210, 2005.

19. Ishikawa M, Kitayama J and Nagawa $\mathrm{H}$ : Enhanced expression of leptin and leptin receptor (OB-R) in human breast cancer. Clin Cancer Res 10: 4325-4331, 2004.

20. Hu X, Juneja SC, Maihle NJ and Cleary MP: Leptin - a growth factor in normal and malignant breast cells and for normal mammary gland development. J Natl Cancer Inst 94: 1704-1711, 2002.

21. Mauro L, Catalano S, Bossi G, et al: Evidences that leptin up-regulates E-cadherin expression in breast cancer: effects on tumor growth and progression. Cancer Res 67: 3412-3421, 2007.

22. Rouet-Benzineb P, Aparicio T, Guilmeau S, Pouzet C, Descatoire V, Buyse M and Bado A: Leptin counteracts sodium butyrate-induced apoptosis in human colon cancer HT-29 cells via NF- $\kappa B$ signaling. J Biol Chem 279: 16495-16502, 2004.

23. Escobar-Morreale HF and San Millán JL: Abdominal adiposity and the polycystic ovary syndrome. Trends Endocrinol Metab 18: 266-272, 2007.

24. Sharma D, Saxena NK, Vertino PM and Anania FA: Leptin promotes the proliferative response and invasiveness in human endometrial cancer cells by activating multiple signal-transduction pathways. Endocr Relat Cancer 13: 629-640, 2006.

25. Sheiness D, Fanshier L and Bishop JM: Identification of nucleotide sequences which may encode the oncogenic capacity of avian retrovirus MC29. J Virol 28: 600-610, 1978.

26. Persson $H$ and Leder P: Nuclear localization and DNA binding properties of a protein expressed by human c-myc oncogene. Science 225: 718-721, 1984.

27. Vita M and Henriksson M: The Myc oncoprotein as a therapeutic target for human cancer. Semin Cancer Biol 16: 318-330, 2006.

28. O'Connell BC, Cheung AF, Simkevich CP, Tam W, Ren X, Mateyak MK and Sedivy JM: A large scale genetic analysis of c-Myc-regulated gene expression patterns. J Biol Chem 278: 12563-12573, 2003.

29. Nesbit CE, Tersak JM and Prochownik EV: MYC oncogenes and human neoplastic disease. Oncogene 18: 3004-3016, 1999.

30. Chung HJ and Levens D: c-myc expression: keep the noise down! Mol Cells 20: 157-166, 2005

31. Skirnisdóttir I, Seidal T, Gerdin E and Sorbe B: The prognostic importance of $\mathrm{p} 53$, bcl-2, and bax in early stage epithelial ovarian carcinoma treated with adjuvant chemotherapy. Int J Gynecol Cancer 12: 265-276, 2002.

32. Oltvai ZN, Milliman CL and Korsmeyer SJ: Bcl-2 heterodimerizes in vivo with a conserved homolog, Bax, that accelerates programmed cell death. Cell 74: 609-619, 1993.

33. Chung TK, Cheung TH, Lo WK, et al: Expression of apoptotic regulators and their significance in cervical cancer. Cancer Lett 180: 63-68, 2002. 